\title{
La protesta social en América Latina: una aproximación a su fisonomía a propósito de los estallidos sociales de 2019
}

\section{Social protest in Latin America: an approach to its physiognomy regarding the social outbreaks of 2019}

Fecha recepción: septiembre 2020 / fecha aceptación: noviembre 2020

Luis Carlos Castro Riaño'

DOI: https://doi.org/10.51188/rrts.num23.418

\begin{abstract}
Resumen
Durante 2019 se precipitó una ola de estallidos sociales en varios países de América Latina, buena parte de ellos en simultáneo. ¿Qué tienen en común unos y otros desde el punto de vista de las acciones de protesta que implican? En este trabajo me propongo responder a este interrogante considerando las movilizaciones de Haití, Ecuador, Puerto Rico, Bolivia, Chile y Colombia. El supuesto general es que pese a las diferencias contextuales y circunstanciales las dinámicas se reproducen a razón de los motivos y procesos. El análisis se basa en los informes periodísticos de diferentes medios y se apoya en presupuestos de la teoría de la movilización social, de la ciencia política y de la filosofía. El objetivo es elaborar una explicación breve, mediata y actual, de la protesta social en la región, dada su vigencia.
\end{abstract}

Palabras clave: democracia; acción colectiva; grupos de interés; estructuras de organización; gramáticas de la vida pública.

\begin{abstract}
Abstrac
During 2019, a wave of social outbreaks was precipitated in several Latin American countries, a good part simultaneously. What do the two have in common from the point of view of the protest actions they involve? In this work I propose to answer this question by considering the mobilizations in Haiti, Ecuador, Puerto Rico, Bolivia, Chile and Colombia. The general assumption is that despite the contextual and circumstantial differences, the dynamics are reproduced due to motives and processes. The analysis is based on journalistic reports from different media and is supported by assumptions from the theory of social mobilization, political science and philosophy. The objective is to elaborate a brief, mediate and current explanation of the social protest in the region, given its validity.
\end{abstract}

Keywords: democracy; collective action; interest groups; organizational structures; grammars of public life.

1 Estudiante de Doctorado en Ciencias Sociales, Universidad Nacional de la Plata. Magíster en Ciencias Sociales; Licenciado en Educación. Docente Corporación Universitaria Republicana, Bogotá, Colombia, Cr 3 N6f-25 (206), Cód. postal 111711. Correo electrónico: lucacas2010@hotmail.com ORCID iD: https://orcid.org/0000-0002-4033-5089 


\section{Introducción}

"Es cierto que el hombre no se resume en la insurrección. Pero la historia actual, con sus contiendas, nos obliga a decir que la rebelión es una de las dimensiones esenciales del hombre. Es nuestra realidad histórica. A menos que huyamos de la realidad, es necesario que encontremos en ella nuestros valores"

(Albert Camus, El Hombre Rebelde)

La protesta social es una forma de participación democrática -basada en la confrontación-, cuyo objeto es transformar situaciones que le son adversas al conjunto de la población o a un sector específico de ella en situaciones benéficas o llevaderas. Esta propiedad se evidencia de forma empírica una y otra vez en todas las sociedades y en su historia, puntualmente en aquellas organizadas como Estado Social de Derecho. Por cierto, se podría afirmar, con una probabilidad extremadamente grande, que a diario en algún lugar del planeta se registra más de una, sólo que no siempre son captadas por los medios de comunicación. Por ejemplo en 2019 se vivió un periodo de grandes agitaciones en varios países de América Latina: en Haití en torno al reclamo por hechos de corrupción y por el deterioro de la situación económica (BBC, 2019, febrero 15)²; en Ecuador a propósito de la finalización de los subsidios al combustible (Garretón 2019); en Puerto Rico para inducir la renuncia del gobernador Ricardo Rosello, máxima autoridad en ese Estado (Nuevo Día, 2019, julio 21); en Bolivia, de una lado, para denunciar un supuesto fraude electoral ante la reelección presidencial de Evo Morales (Miranda, 2019), de otro, para intentar restituir el orden constitucional ante su destitución (Lizágarra y Vacaflores, 2019); en Chile para hacer contención a políticas de arancelamiento y para demandar la renuncia del primer mandatario de ese Estado; en Colombia para frenar reformas de tipo laboral, pensional y tributario, y para denunciar el asesinato de líderes sociales e indígenas (Suárez, 2019).

Ciertamente se trata de fenómenos complejos en todo el sentido de la palabra que además no siempre tienen buena aceptación ni surten la misma efectividad. No obstante, más allá de sus particularidades y de la heterogeneidad de los contextos, todos estos casos comparten dos factores elementales: los motivos que los precipitaron, es decir las causas que determinan su devenir, y los procesos que los materializaron, esto es, las maneras de hacer o lograr propósitos colectivos. ¿Qué tienen en común unos y otros desde el punto de vista de las acciones de protesta que conllevan?, en los próximos apartados procuro resolver esta cuestión deteniéndome en los más comunes.

El texto presentado se basa en información que recabé mediante un ejercicio de observación participante en protestas sociales realizado entre 2009 y 2019, en varios países de la región (Ecuador, Perú, Bolivia, Argentina, Uruguay, Chile,

2 Las protestas antigubernamentales son comunes en este país. Al igual que en 2019. en 2018 se precipitaron en varias oportunidades por la devaluación de la moneda, la escasez y las alzas en la gasolina. 
Colombia y México), que incluyó conversaciones informales desarrolladas con promotores elegidos al azar. El examen recupera ejercicios investigativos propios, efectuados en el marco de estudios de posgrado que discurren sobre la acción colectiva de los estudiantes y de las mujeres en Argentina, y la transformación de los mecanismos y procesos de la protesta social en Colombia. El insumo principal está compuesto por informes sobre los episodios mencionados publicados en diarios digitales y por artículos de investigación que versan sobre protestas de sectores específicos en la región.

El análisis es comparativo, toma herramientas teóricas de la movilización social, de la ciencia política y de la filosofía, y valora en concreto aspectos como: a) la definición conceptual; b) los antecedentes históricos; c) las lógicas de conformación que facilitan el desarrollo de las movilizaciones; d) las relaciones que vinculan a los sujetos que las promueven y la funcionalidad de aquellos que se suman de forma espontánea o premeditada a su cauce; e) los actos particulares que desarrollan unos y otros; f) la forma en que se constituye el lenguaje y el significado público del fenómeno en sí mismo, a saber: la configuración de su sentido; y g) las respuestas institucionales a las demandas y confrontaciones. La apuesta última es difundir una explicación abarcadora -nunca acabada pero sí actual, objetiva y crítica- en relación a su significado y a los procesos que orquestan y determinan su desarrollo.

\section{Concepto}

Antes de adentrarse en la reflexión sobre este asunto conviene establecer de qué se trata, es decir: ¿de qué hablamos cuando hablamos de protesta social? En ese sentido es prudente advertir que el término es polisémico y que recibe su connotación de acuerdo al campo de conocimiento que lo interpela. Así, su concepción depende, propiamente, de las orientaciones ideológicas de su enunciación, cuanto más cuando se trata de un concepto cuya acción trasciende en la naturaleza política de la sociedad. Por ende: para algunos será un acto de emancipación inspirado en los derechos fundamentales del individuo y para otros una expresión de subversión inspirada en ideologías de izquierda; para unos una forma de expresión espontánea, producto de las desigualdades materiales y para otros un hecho que amerita reproche, repudio social, regulación y condena

En consecuencia a lo largo de la historia se la ha etiquetado de diferentes formas: revuelta, motín, lucha de clases, revolución, rebelión, conducta, movimiento social, etc. (Castro, 2018). De allí que su significación, como veremos, aluda los conflictos entre grupos de interés. En esta lógica, siguiendo a Fillieule y Tartakowsky (2020), lo que cambia no es propiamente su forma, "sino su sentido y su interpretación”, los cuales, como contrapartida, contribuyen a transformar su morfología. Considerando esas paradojas aquí se la define -a razón de su génesis y su reproducción- como una forma de "acción social colectiva" (Archila, 2018), instrumental en tanto sigue objetivos y expresiva en tanto indica descontento, cuya finalidad última es hacerle frente a las determinaciones de las fuerzas políticas que rigen al Estado. 
Esta acepción, por una parte, surge del pensamiento weberiano según el cual el fenómeno que estamos observando corresponde al tipo de "acción racional con relación a fines" 3 . Es decir, a un acto que se orienta "por un sentido (subjetivo) poseído o mentado, no interesa si de manera más o menos inadvertida”, realizado por "los sujetos de la acción" (Weber, 1990, p. 177). Actúa de esta forma "quien oriente su acción por el fin, medios y consecuencias implicadas en ella y para lo cual sopese racionalmente los medios con los fines, los fines con las consecuencias implicadas y los diferentes fines posibles entre sí" (Weber, 2002, p. 21).

Por otra parte, se apoya en la epistemología de la movilización social en tanto asume esta cuestión como: a) una expresión de acción colectiva que promueve la transformación de circunstancias adversas en benéficas; b) adopta diferentes formas "puede ser breve o mantenida, institucionalizada o subversiva, monótona o dramática” (Tarrow, 2004, p. 24); c) involucra múltiples procesos concertados de manera más o menos simultánea; d) se materializa en torno a esquemas de interpretación que permiten a los individuos "ubicar percibir, identificar y clasificar los acontecimientos que tienen lugar dentro de su espacio vital y en el mundo en general" (Goffman, 1974, como se cita en Snow, Rochford, Worden y Benford, 1986, p. 32); e) se consolida con base en la conformación o existencia previa de identidades colectivas y a partir de sentimientos de solidaridad (Melucci, 2010); y f) reúne objetivos y prácticas propias de los "movimientos sociales", por ejemplo, su orientación hacia el cambio (Munck, 1995), sus modos actuar colectivamente (Tilly y Wood, 2010) o sus construcciones simbólicas, sin que ello implique, necesariamente, instancias organizativas formales o prolongadas.

Protestas y movimientos resultan de la acción deliberada de grupos de interés en contextos políticos concretos. Sin embargo, la diferencia entre las dos consiste básicamente en el grado de organización y en los periodos de visibilidad. En el caso de los movimientos, interactúan tres elementos en conformidad con Tilly y Wood: 1) un "esfuerzo público organizado y sostenido" por denunciar ante las autoridades las demandas colectivas (léase campañas); 2) repertorios de movilización, es decir, uso combinado de formas de acción política como "coaliciones y asociaciones con un fin específico, reuniones públicas, procesiones solemnes, vigilias, mítines, manifestaciones, peticiones, declaraciones a y en los medios públicos y propaganda"; 3) manifestaciones públicas concertadas de valor, unidad, número y compromiso por parte de los participantes (léase "WUNC" por sus iniciales en inglés), sean actores o partidarios (2010, p. 22).

\footnotetext{
3 Weber sostiene que los individuos actúan de forma distinta, según las circunstancias que atraviesan y que sus acciones se pueden agrupar en cuatro tipos, ideales, en virtud de su análisis: "1) racional con arreglo a fines: determinada por expectativas en el comportamiento tanto de objetos del mundo exterior como de otros hombres, y utilizando esas expectativas como "condiciones" o "medios" para el logro de fines propios racionalmente sopesados y perseguidos. 2) racional con arreglo a valores: determinada por la creencia consciente en el valor -ético, estético, religioso o de cualquiera otra forma como se le interprete- propio y absoluto de una determinada conducta, sin relación alguna con el resultado, o sea puramente en méritos de ese valor, 3) afectiva, especialmente emotiva, determinada por afectos y estados sentimentales actuales, y 4) tradicional: determinada por una costumbre arraigada". (Weber, 2002, p. 20)
} 
En el caso de la protesta, de acuerdo a la observación participante realizada, ciertamente se presentan los tres aspectos sólo que con una escala muy inferior; la dimensión organizativa es fundamental pero no implica necesariamente la intervención de organizaciones globales ni de organismos profesionales para su fomento; y los momentos visibles de las confrontaciones son mantenidos pero no sostenidos en el tiempo como ocurre con los movimientos, por ejemplo el Movimiento de los Trabajadores Rurales sin Tierra (MST) en Brasil, que surge en la década del setenta y mantiene sus acciones en la actualidad (Saccone, 2019) ${ }^{4}$. Las protestas, a diferencia de los movimientos, suelen ser la instancia alternativa -ocasional- de grupos de interés y, por lo mismo, son efímeras y fugases cuando no logran masificarse. Las que se prolongan en el tiempo por lo general se transforman en movimientos, a veces constituidos por la articulación de los existentes; cuando esto ocurre en algunas circunstancias se convierten en actividades periódicas que se realizan en fechas especiales, en el marco de alguna conmemoración gremial, ejemplo el Día Internacional de los Trabajadores o el Día Internacional de la Mujer.

Además, las reivindicaciones de los movimientos no siempre son democráticas. Tal como nos muestra la historia del último siglo han existido movimientos "que plantean, una y otra vez, programas antidemocráticos, como la exclusión de minorías raciales, étnicas o religiosas, e incluso, de vez en cuando, la abolición de la democracia en nombre de un credo totalitario" (Tilly y Wood, 2010, p. 245). En la protesta ocurre todo lo contrario: primero, sus demandas expresan un carácter puramente democrático en cuanto afirman la soberanía ciudadana; segundo, adquieren su justificación en torno a aspectos vinculados con la lógica racional que sostiene al Estado contemporáneo -esto es la voluntad general-, pese a que sus gramáticas de articulación no aludan explícitamente la democracia.

\section{Antecedentes}

Desde el punto de vista histórico "hace miles de años que, en todo el mundo, el pueblo se rebela por un motivo u otro" (Tilly y Wood, 2010, p. 20). En nuestros días esa rebeldía condensa movimientos sociales cuando alcanza un grado elevado de organización y logra sostener confrontaciones masivas de forma prolongada. En otras épocas -cuando demandó la toma del poder- catalizó revoluciones, guerras civiles y luchas armadas, incluyendo sus excesos. Sin duda su papel ha sido clave en la emergencia del Estado moderno, en sus planos social, jurídico y democrático; esta expresión ha fungido como un factor de transformación de las sociedades desde tiempos inmemorables y, oponiéndose al orden establecido, se ha constituido como su presupuesto.

De acuerdo con Tilly y Wood, desde mucho antes de la segunda mitad del siglo XVIII los ciudadanos británicos y norteamericanos habían realizado "reivindicaciones públicas" de varios tipos. "Dentro de unos límites, los artesanos organizados

4 Este movimiento nace oficialmente en 1984 como una organización de campesinos que luchan en Brasil por la reforma agraria, ocupando tierras improductivas o embargadas. En la actualidad, de acuerdo con el informativo internacional France 24, "se ha convertido en el mayor productor de arroz orgánico de América Latina, según datos oficiales del Gobierno de Río Grande do Sul” (Saccone, 2019). 
y las milicias desfilaban con motivo de sus festividades y aprovechaban en ocasiones ese derecho para manifestar su oposición a personajes poderosos o a programas coercitivos" (Tilly y Wood, 2010, p. 52). El consenso y la organización giraban en torno a la resistencia y a la venganza contra quienes quebrantaban los derechos - la moral local. Las cacerolas, en esos días, se implementaban para acosarlos en sus casas y "armar jaleo golpeando ollas y sartenes, lanzando insultos y cantando canciones obscenas" (p. 52.). Era tal la frecuencia que ya para 1750 existía un grupo de leyes que regulaban las movilizaciones en algunos países de Europa.

Las formas que conocemos en la actualidad se comenzaron a perfeccionar durante la guerra de los siete años (1756-1763) y fueron la base de hechos como la independencia de las colonias británicas de norte América (independencia de los Estados Unidos 1776-1783) o la revolución francesa (1789-1799). La República liberal se materializó por efecto de la protesta, y de la acción contrahegemónica que ésta implica, allende a las fuerzas que la pusieron en marcha. Igualmente ocurre con los derechos civiles, laborales y sociales de los cuales disfrutamos en la actualidad: gracias a la protesta se hizo extensiva la categoría de ciudadano y con ello el derecho al sufragio, se equipararon los derechos patrimoniales, se hicieron soportables los horarios de trabajo y quienes dependen de un salario para sus sustento disfrutan de prestaciones y posibilidades de pensión. El inconformismo, y la insumisión en sus diversas expresiones, han hecho posible que la educación y la salud -dos instancias que en otros tiempos eran del disfrute exclusivo de grupos privilegiados- hoy sean concebidos como bienes públicos; la organización e insistencia han permitido que en varios países, incluso de nuestra región, su prestación sea de calidad y su acceso sea libre y gratuito. Con Fillieule y Tartakowsky "la manifestación callejera solo se autonomiza y se afirma como modalidad de acción política con el surgimiento de una esfera pública y con la consolidación de las democracias parlamentarias" (2020, p. 70.) En este orden de ideas la protesta es un galardón de la conquista del sufragio universal; por cierto, durante la conformación del Estado moderno quienes se manifestaban aspiraban a convertirse en ciudadanos.

En el territorio latinoamericano este fenómeno se registra desde épocas de la colonia, en el virreinato del alto Perú, en hechos como el levantamiento de Túpac Amaru II, en 1780 (Galeano, 2015), y en el virreinato de la nueva granada con la insurrección de los comuneros, en 1781. A lo largo del siglo XIX -desde luego no como lo conocemos en nuestro tiempo pero sí como una forma de acción colectiva contenciosa de un grupo de interés contra otro- mecanizó los procesos independentistas, así como los combates realistas/patriotas, las lidias federalistas/centralistas y los conflictos entre conservadores y liberales. En el siglo XX hizo lo propio en las luchas obreras, en los populismos, en la lucha armada y en las pugnas por la democratización del Estado, así como en las contiendas políticas particulares de cada país ${ }^{5}$.

En consecuencia el ejercicio de la protesta ha sido un factor elemental en el desarrollo de dos procesos que les son esenciales al Estado Social de Derecho: la democracia, entendida como un tipo de régimen en el cual existe un "conjunto de reglas (primarias o fundamentales) que establecen quién está autorizado para

5 Las consideraciones socio-históricas, pormenorizadas, de la protesta social en América Latina, al igual que sus tendencias, se pueden consultar en Calderón (2012). 
tomar las decisiones colectivas y bajo qué procedimientos" (Bobbio, 2014, p. 24); y la democratización de ese aparato, entendida como "todos los pasos que da un régimen para alcanzar un mayor grado de regularidad, amplitud, igualdad, consultas vinculantes y protección" (Tilly y Wood, 2010, p. 245). Por cierto, el declive de uno y otra ha repercutido en la criminalización, represión y deceso de las reivindicaciones sociales; de ahí que la contracción de los derechos democráticos también se evidencie en el auge y caída de la protesta social.

En la medida en que se ha incrementado el número de grupos capaces de organizarse, las sociedades se han hecho pluralistas -y las relaciones sociales se han tornado inextricables-, la protesta se ha configurado como una instancia de participación para la defensa y promoción de los derechos fundamentales. Esto es trascendental para el orden social democrático en términos de participación porque, si bien la democracia establece el consenso de la mayoría, también requiere -necesariamente- el disenso de la minoría (Bobbio, 2014) y porque en una sociedad democrática los desacuerdos respecto de cómo administrarla no sólo son legítimos sino necesarios (Mouffe, 2014). De aquí que la protesta esté contemplada y garantizada en la carta magna de las organizaciones que se autodenominan como "Estado Social de Derecho", una sociedad de este tipo "en la que el disenso no esté permitido es una sociedad condenada a morir" (Bobbio, 2014, p. 70). Así pues, el disenso de las acciones de protesta expresa dos aspectos centrales para su realización: 1) "la representación", en tanto implica "la posibilidad de presentar intereses y demandas" pero también permite "seguir siendo diferente y nunca ser completamente oído"; y 2) "la participación", en cuanto, involucra la toma de una posición respecto de una situación, "esto es, actuar para promover las necesidades e intereses de un actor", y permite "pertenecer a un sistema, identificándose con los intereses generales de la comunidad” (Melucci, 2010, p. 173).

Por supuesto en términos negativos las acciones de protesta alteran el orden público, entorpecen el funcionamiento de los sistemas que lo regulan (educación, transporte, abastecimiento, salud, justicia, etc.) y suelen lacerar la economía en la medida en que detienen la producción de bienes y servicios. Además, acarrean pérdidas materiales que incluyen daños a la propiedad pública y privada y, muchas veces, causan perjuicios que pueden llegar a ser irreparables. No obstante, en términos positivos, visibilizan las relaciones de poder y hacen posible la negociación e instauración de acuerdos públicos.

La protesta, en contraste, desestabiliza y consolida a la vez el orden social. Es decir, mientras lo altera y lo lleva a límite, devela las urdimbres que lo sostienen y, cuando logra su fin, sienta las bases ya sea para instituir uno nuevo o para hacer mejoras en el existente. En pocas palabras, su ejercicio permite un acercamiento entre el Estado y el cuerpo político que lo compone, a saber: los ciudadanos. Parafraseando a Melucci (2010), puede ser considerada como un "espacio público" -vital en el funcionamiento de las sociedades democráticas contemporáneasen cuanto "sistema móvil de instancias" que se mantienen abiertas debido a la contienda regular entre la ciudadanía y las instituciones. 


\section{Presupuestos básicos}

Los actos de inconformismo característicos de los fenómenos de protesta social adquieren su legitimidad en el devenir de los procesos políticos, nunca fuera de ellos. Por consiguiente siempre existe la posibilidad de que emerjan y se instalen en la agenda pública; "lo que varía ampliamente con el tiempo y el lugar son el nivel y el tipo de oportunidades que la gente experimenta, las restricciones a su libertad de acción y las amenazas que perciben sobre sus intereses y valores" (Tarrow, 2004, p. 109). En los casos señalados en la introducción las protestas se precipitaron particularmente por la aplicación de políticas económicas, el mal manejo del Estado, escándalos relacionados con la corrupción, o por la ofensa explícita contra opositores como ocurrió en Puerto Rico ${ }^{6}$ a raíz de la filtración de un "chat". En la historia reciente se han desencadenado en torno a reformas agrarias, a proyectos de redistribución de la tierra y la riqueza; en rechazo a políticas que laceran la educación, la salud o la soberanía alimentaria; en pro de la creación de leyes de género; y debido a persecuciones, al encarcelamiento o al asesinato de líderes y activistas sociales (Almeida y Cordero, 2017), como ocurrió en Argentina en 2017 (Escandar, 2017), en Chile en 2018 (BBC, 2018, noviembre 16) o en Colombia también en 2018 y 2019 (Infobae, 2018, julio 07; Oquendo, 2019).

Estos fenómenos se precipitan, en especial, cuando se exacerban los roces entre los sectores dominantes de la sociedad y cuando disminuye la acción represora de los organismos encargados del orden. Por consiguiente son alicientes aspectos como las tramas políticas que se estén desarrollando a nivel local, nacional o internacional, las contradicciones de intereses entre sectores sociales, las penurias súbitas y los cambios institucionales e ideológicos, del poder (McAdam, 1999). Para que las demandas adquieran la categoría de problemas públicos y se instalen en la agenda política, es determinante el juego político del oficialismo y la oposición en relación al control de los poderes del Estado. Las acusaciones constantes entre diferentes actores y sectores, así como las denuncias respecto de las falencias del sistema y los escándalos, atizan las posibilidades del estallido social, que finalmente tiene lugar cuando las partes se identifican a razón de la relación nosotros/ ellos y no logran establecer acuerdos. Cuando éstos se concretan, o se presentan ceses de actividades en los espacios en los cuales se toman las decisiones políticas que condicionan a la sociedad civil, devienen periodos de reflujo social.

Siguiendo a Mouffe, la dimensión política de la sociedad se compone de dos instancias: "la política” y "lo político". La primera corresponde a las actuaciones que la sostienen -es decir a su existencia misma- y es definible como un "conjunto de prácticas, discursos e instituciones que busca establecer un determinado orden y organizar la coexistencia humana en condiciones que siempre son potencialmente conflictivas" (2014, p. 22). La segunda se refiere a la esencia, a las propiedades y al modo en el que se instituye la sociedad, es decir, a "la dimensión antagónica que es inherente a todas las sociedades humanas". "Lo político" entonces está relacionado con las "formas colectivas de identificación" que tienen su realización a partir de

6 En dicho "chat" el gobernador Ricardo Roselló y 11 hombres de su entorno compartían mensajes ofensivos hacia periodistas, funcionarios, mujeres, gays y víctimas del huracán de 2017 (El Espectador, 2019, junio 24). 
la comparación y la diferencia, en la medida que "en este campo siempre estamos tratando con un nosotros en oposición a un ellos" (págs. 22 y 23). En esta instancia se constituye la identidad colectiva que implica el establecimiento de una diferencia construida de manera jerárquica. Ésta es relacional y la afirmación de una diferencia es precondición de su existencia (Mouffe, 2011). La relación nosotros/ ellos resultante alberga, por lo tanto, un carácter antagónico que, en circunstancias específicas, se convierte en una relación "amigo/enemigo" en donde el objetivo de las partes es la eliminación del otro.

Los procesos políticos están condicionados por estas dinámicas en la medida en que -siendo continuos- son la expresión de formas antagónicas de relaciones entre grupos de interés y de prácticas hegemónicas de articulación social que, en periodos de contingencia, crean un determinado orden y fijan el significado de sus instituciones. Las protestas sociales son inherentes a su desarrollo. Por consiguiente sus expresiones son contrahegemónicas, en tanto evidencian que "las cosas siempre podrían ser diferentes"; e intermitentes, en cuanto el orden constantemente "se afirma sobre la exclusión de otras posibilidades" (Mouffe, 2014, p. 22).

\section{Grupos de interés}

Lo que en un momento dado se acepta como "orden natural", junto con el sentido común que lo acompaña, es el resultado de "prácticas hegemónicas sedimentadas" que se han instalado sobre otras formas de orden precedente. El ser humano históricamente ha conformado grupos para superar las adversidades que el devenir pone frente a él: hordas, clanes, tribus, pueblos, ciudades-estados, naciones, imperios y repúblicas. Por ende en todas las épocas han surgido organizaciones que, en momentos de contingencia, se han convertido en fuerzas decisivas, siendo los conflictos los vehículos para su articulación su reforma y su progreso. El momento actual no hace la diferencia: los sujetos se asocian para garantizar la realización de sus intereses individuales y colectivos conformando grupos de interés.

Uno de los objetivos centrales de la asociación, si bien no existe una finalidad única, es precisamente la protección de los intereses de sus integrantes tal cual rezan las constituciones republicanas. Su función elemental es la provisión de los recursos -entiéndase de los "bienes públicos"- necesarios para garantizar la existencia (Olson, 1992). Éstos adquieren su relevancia de acuerdo a las necesidades de cada cual y éstas, a su vez, están determinadas por el origen socioeconómico de cada uno. Todo junto, sumado a su disponibilidad y a su finitud, hace que los grupos entren en contradicciones irreconciliables y, finalmente, en disputas -algunas a muerte- por su obtención y monopolio; los grupos que logran constituir organizaciones sólidas son los que establecen el orden de las cosas e imponen su hegemonía.

Con el transcurrir del tiempo el número de individuos capaces de conformar agrupaciones y organizarse se ha ido incrementando, la sociedad se ha hecho pluralista y las identidades colectivas que encarnan estas formaciones han estado demarcadas por la proliferación de oficios y por la diversidad de sus integrantes. 
Históricamente los aventajados han sido los que catalizan las oportunidades para la protesta; sus diferencias de intereses, y las tensiones que se producen entre ellos, son las que modelan las posibles reivindicaciones. Los grupos restantes tienden a optimizarlas estableciendo relaciones directas con sus problemáticas y adecuándolas a la particularidad de sus propias necesidades. La heterogeneidad ideológica y las diferencias socioeconómicas son superadas, cuando las situaciones lo ameritan, por medio de pactos y alianzas, establecidas -de arriba hacia abajo o viceversa- entre unos y otros. Esta es una de las causas por las cuales en nuestra época se conforman coaliciones políticas en momentos de elecciones, y emergen frentes de lucha en tiempos de protestas, generalmente entre sectores afines y eventualmente entre grupos adversos.

En los Estados Latinoamericanos estas lógicas se desarrollan a la cabeza de las acciones de grupos de poder, regularmente por los desacuerdos en el marco de los procesos políticos. Los grupos restantes o sectores subalternos (asociaciones profesionales, gremios, sindicatos, organizaciones comunitarias, colectivos, etc.) pugnan por sus intereses recurriendo a la protesta, según sus condiciones, en medio del forcejeo entre los más fuertes. En ocasiones toman la iniciativa o se articulan a las movilizaciones de acuerdo al contexto y sólo cuando suman las fuerzas suficientes, o realizan coaliciones significativas, logran trascender en el escenario público (Diani, 2015). En Ecuador los gremios de taxistas y autobuses respondieron a las decisiones del gobierno con una huelga indefinida que finalmente fue dirigida por los colectivos indígenas (Semana, 2019, octubre 15). En Puerto Rico se registró la participación de la Unión de Trabajadores de la Industria Eléctrica y Riego, la Coordinadora Sindical, la Asociación Puertorriqueña de Profesores Universitarios y la Central Puertorriqueña de Trabajadores, entre otros (Nuevo Día, 2019, julio 21). En Colombia "Lo que en principio comenzó como un paro nacional convocado por las centrales sindicales y obreras del país, derivó en movilizaciones de todos los sectores de la sociedad” (Suárez, 2019, s. pág.).

Por todos estos motivos hoy en día es habitual que: 1) las expresiones de indignación aglomeren individuos diversos - de diferentes sectores y estratos-; 2) las problemáticas sociales no tengan la misma resonancia en todos los países que integran la región, pese a configurarse sobre los mismos móviles; y 3) que incluso sean protagonizadas por sectores políticos de derecha. Esto último de hecho se viene intensificando en la región y ha ocurrido recientemente en Estados como Venezuela, Nicaragua y Bolivia. En el caso boliviano durante el estallido aludido se movilizaron grupos de oposición y afines al gobierno aymara (CNN, 29 de octubre de 2019); los primeros implementaron un elemento en común "la defensa de la democracia y el voto" logrando movilizar entre cinco mil y trece mil personas a diario, durante un mes aproximadamente (Levy y Rebón, 2020). 


\section{Actores y partidarios}

En ocasiones las protestas entrañan un carácter inorgánico, es decir, no siempre provienen de la acción de grupos afianzados. El caso Chileno es un ejemplo claro: si bien las protestas aludidas nacen de la insubordinación de los estudiantes de secundaria el estallido fue protagonizado por "sectores medios populares, que han salido de la pobreza pero viven en permanente endeudamiento y sectores medios emergentes, quienes ya tienen un cierto nivel de vida y aspiran a más" (Garretón, 2019, apartado "sectores que se movilizan"). Tampoco son, necesariamente, iniciativa de los oprimidos. Eventualmente pueden surgir ante el espectáculo de la opresión contra otro, ya sea por identificación psicológica, por solidaridad o porque, como dijese Camus, "no se soporte ver cómo infligen a otros ofensas que nosotros mismos hemos sufrido sin rebelarnos" (Camus, 2015, p. 32). En la actualidad es muy común que personajes de la farándula se solidaricen y engrosen sus filas, en Puerto Rico, por ejemplo, hubo episodios liderados por artistas como Ricky Martin, Residente, Bad Bunny y Daddy Yankee (La Izquierda Diario, 2019, junio 25).

De cualquier modo esta expresión, en tanto producto del hacer social, depende directamente de la agencia de los actores, de sus organizaciones y del número de partidarios que se solidaricen con sus demandas. Unos y otros "interactúan, se influyen recíprocamente, y negocian, para definirse como actor colectivo y para delimitar el ámbito de su acción” (Melucci, 2010, p. 63), no obstante, siempre es posible que el panorama de los bienes públicos en juego sea más diáfano para los primeros. Entre éstos se encuentran los líderes y los activistas o militantes ${ }^{7}$ de la causa. En nuestros tiempos son personas jóvenes, o relativamente jóvenes, que provienen en su mayoría de las "nuevas clases medias", cuentan con altos niveles de educación, regularmente se integran a instituciones con carácter social y participan de actividades de la misma índole; sus prácticas incluyen funciones administrativas y logísticas para sus agrupaciones, de forma permanente o esporádica, a cambio de algún bien o ad honorem.

Los partidarios entre los que se encuentran los seguidores, amigos y familiares de los actores, representan la fuerza potencial para alcanzar el éxito. Su grueso pertenece a sectores medios y a sectores pauperizados que no constituyen una fuerza organizada homogénea pero que tienen mucho en común en tanto están atravesados por las mismas problemáticas sociales. Ellos se adhieren en el transcurso de las querellas - de manera interesada o desinteresada, temporal o permanente- en la medida en que se sienten identificados con las ideas que expresa la protesta; en que poseen intereses compartidos, son afectados por los problemas denunciados o los visualizan en sus espacios de interacción. Dicho brevemente: en

\footnotetext{
7 "En el mundo contemporáneo, el término cuenta con dos acepciones de uso corriente: militante suele designar a aquel que integra y participa, de forma orgánica y activa, en una organización política partidaria o de otro tipo (así se habla de militantes sindicales, militantes estudiantiles, militantes sociales); también se emplea como sustantivo o adjetivo para aludir a una condición o conducta personal orientada a la realización de una causa (...). En la arenas públicas y mediáticas, el debate se desarrolla valiéndose de dos imágenes de militante: de un lado, el auténtico militante, guiado por la convicción, la conciencia y la entrega desinteresada a una causa; del otro, el militante de aparato, ése que, impulsado por intereses mezquinos, o apartado del libre pensamiento y la voluntad transformadora, opta por guardar fidelidad a la etimología de su condición y oficiar de soldado de sus dirigentes” (Quirós, J. 2014 p. 251).
} 
la medida en que experimentan las inconsistencias o contrariedades del sistema social en su propio hacer y cotidianidad.

Todos en su rol de ciudadanos participan de la reproducción de las gramáticas de la protesta y expresan su apoyo promoviendo sus prácticas. Hoy por hoy el uso de las tecnologías de la información y la comunicación facilitan su intervención -de manera individual y/o autónoma- mediante la creación de símbolos y mensajes gráficos que ponen en circulación por las redes sociales. Estos medios permiten la multidireccionalidad de los flujos de información, la creación de "canales informales de diálogo que generan una comunicación más fluida" y "la opción de anonimato de los participantes" (Castells, 2009, p. 260). En el plano de la transformación es prudente anotar que en las últimas décadas internet se ha convertido en un espacio público etéreo donde se expresan y desarrollan nuevas formas de poder. De acuerdo con Calderón, su frecuencia en el uso "tiene un efecto positivo sobre la participación de los ciudadanos en protestas y manifestaciones callejeras” (Calderón, 2012, p. 258).

\section{Dinámicas de la movilización}

Las confrontaciones suelen originarse durante el desarrollo de los procesos políticos, sobre la base de las decisiones que dependen del Estado o sus instituciones, y extenderse entre la ciudadanía en general. Líderes y activistas configuran inicialmente las primeras lecturas de la realidad con el fin de concentrar la opinión pública en circunstancias o hechos injustos. Para ello elaboran una serie "marcos" y "enmarcados" (Snow y Benford, 1988; Cefaï, 2008) -léase "esquemas de interpretación" en los que atribuyen y articulan las creencias y los significados necesarios para insuflar el inconformismo y legitimar las acciones contenciosas- que se popularizan con frases o eslóganes. En Puerto Rico se acompañaron de la voz masiva "renuncia Ricky" (El Espectador, 2019, julio 24), en Bolivia hubo dos tendencias, la del nuevo oficialismo que se tomó las calles de las principales ciudades al grito de "nadie se rinde nadie se cansa" (Miranda, 2019), y la del sector Aymara que hizo lo propio rotulando al gobierno de facto de "golpista", "dictador" y "represor" (Lizárraga y Vacaflores, 2019). En Chile se masificaron las frases "no estamos en guerra, estamos unidos", "no son 30 pesos, son 30 años" y "Chile despertó" (Gil, 2019), enunciado que también se implementó en el episodio colombiano -sin la misma recepcióncomo "Colombia despertó".

En paralelo a la intensificación de la interacción entre los grupos de interés se conforman las estructuras organizativas y se crean las redes de organizaciones de base que se encargan, entre otras funciones, de articularlas, de coordinar las acciones, y de movilizar los recursos. En el transcurso de todos estos procesos se producen incentivos y se concertan planes para convertir las demandas en expresiones de confrontación colectivas. La materialización de las campañas incluye la realización de diversos encuentros (debates, mítines, juntas, etc.), una difusión rápida de los sectores más activos a los menos activos, alianzas entre unos y otros, "un ritmo de innovación acelerado en las formas de confrontación, marcos nuevos o transformados para la acción colectiva, una combinación de participación 
organizada y no organizada y unas secuencias de interacción intensificada entre disidentes y autoridades" (Tarrow, 2004, p. 202). Su ímpetu y duración puede conducir a sus contrincantes a posiciones críticas. De acuerdo con las unidades de análisis se puede hablar de "oleadas", ciclos cortos con bajos niveles de sustentabilidad donde, de acuerdo con Álvaro García Linera, "las fuerzas de renovación son de corta duración" (Levy y Rebón, 2020, cuarto párrafo). En Chile, con una frecuencia semanal que duró meses, la revuelta social precipitó una crisis política, develó problemáticas estructurales que anteriormente carecían de atención o apoyo, y llevó a la sociedad entera a considerar la necesidad de hacer reformas profundas a la Constitución Política Nacional (Montes, 2020).

En simultáneo al desarrollo de las protestas las redes realizan varios procesos. Algunos requieren un esfuerzo particularmente cognoscitivo por tratarse de actividades en las que predomina el uso del intelecto, otros son más bien operativos por tratarse de la puesta en funcionamiento de las tácticas y de los mecanismos de persuasión. Todos se complementan ya que implican ejercicios de una u otra índole, retroalimentan el formato organizativo de cada sector y pretenden la movilización masiva de la sociedad. No obstante, ambos son diferenciales pues mientras que los procesos cognoscitivos se basan en la consolidación del consenso colectivo, en el diseño de la protesta y en la justificación de la masificación, los operativos implican la conjugación de los medios, la difusión del consenso y la ejecución del método para materializar la unidad.

En general, 1) se configuran nuevos esquemas de significación que reúnen las atribuciones y señalamientos de varias organizaciones, esto es "marcos maestros" que tienen por finalidad articular fuerzas y movilizar a la sociedad (Snow y Benford, 1988; 1992); en los casos que estamos examinando se volvieron a escuchar frases clásicas como "Latinoamérica despertó" o "el pueblo unido jamás será vencido". 2) Se implementan "repertorios modulares" de acción (Tilly, 2000), es decir, una serie de tácticas o estrategias de confrontación tradicionales. 3) Actores y partidarios construyen un nosotros colectivo que les proporciona las bases emotivas para solidarizarse unos con otros y aventurarse a la acción; éste nosotros se cristaliza en la "identidad colectiva", en "formas organizacionales, sistemas de reglas y relaciones de liderazgo" (Melucci, 2010, p.66) y constituye un ejercicio continuo tanto de los grupos consolidados como de organizaciones que subsisten en tiempos de reflujo social. Y 4) se crean nuevas modalidades para actuar colectivamente; por ejemplo en Chile, durante los acontecimientos señalados, los estudiantes, que fueron los primeros en sublevarse realizando "evasiones masivas" en el metro de Santiago; el acto consistía en evadir los torniquetes para ingresar a los andenes (Paul, 2019). Igualmente allí, y en varias de las ciudades de países como Puerto Rico o Colombia, miles de personas hicieron sonar sus cacerolas en las calles, desde las ventanas de casas y apartamentos, en rechazo a restricciones como "toques de queda" (Nuevo Día, 2019, julio 21; Infobae, 2019, noviembre 21). En lugares como Bogotá y Medellín, lo largo de las marchas, se desarrollaron eventos como "un canto por Colombia", iniciativa que reunió más de 300 artistas nacionales y que consistió en la realización de varios conciertos (Semana, 2019, diciembre 08). 


\section{Gramáticas y sentidos}

El sentido que adquieren las acciones de la protesta social es sustancial para el logro de sus objetivos; de hecho este factor es la base de una de las explicaciones a las causas por las cuales la gente se suma o se mantiene al margen del asunto. Su razón mentada se configura en la antesala, en el transcurso y después de las confrontaciones. Es efecto de la acción racional de los actores en pugna y se manifiesta de manera singular en las gramáticas del hacer colectivo. Siguiendo a Wittgenstein (2017), éste puede situarse en lo que él denominó los "juegos del lenguaje" o "formas de vida" que constituyen en el tiempo los significados de las expresiones en el plano conceptual y comportamental. El lenguaje en esta lógica se concibe como una actividad humana en donde las palabras son herramientas que se articulan para crear las ideas que evocan elementos lingüísticos. Se sigue entonces que el sentido es construido, al igual que aquel en tanto hecho social, y que: 1) deviene expresado en sus gramáticas, esto es en las reglas o normas para hablar compartidas por una comunidad o sociedad; 2) no va más allá de las circunstancias de su uso; y 3) está directamente relacionado con el contexto en donde tiene lugar, con los rasgos de la vida de sus emisores y con su hacer colectivo.

Ahora bien, tanto los actores de la protesta como sus adversarios configuran las gramáticas que la dotan de razón, independiente de que su propósito sea insuflar o estigmatizar sus acciones. Unos y otros la denotan expresando sus identidades, adjetivando a sus contrincantes y adjudicándoles acciones siniestras que inducen al repudio social. El fin último de ambos es impactar en la opinión pública; en el caso de los primeros para satisfacer las necesidades demandadas; en el caso de los segundos para desaprobar las reivindicaciones y avalar los actos de represión o evasión que implementan. En este orden de ideas "los juegos del lenguaje" cumplen una función inductiva en la ciudadanía y configuran su cognición en torno a la protesta. Así pues, su significado es producto de la misma lucha, entra en el campo de la disputa entre los grupos de interés y depende de las capacidades de éstos para masificarlo e instalarlo en la "conciencia pública” (Gusfield, 2014).

En ambos casos las gramáticas son híbridos de la ideología -así como de los elementos de la cultura, de los procesos políticos y de los determinismos históricos de cada contexto- y viajan por los medios de información. Los adversarios -que por lo general se encuentran aglomerados en el Estado o en las instituciones que lo componen- implementan unas gramáticas despojadas de su carácter dialéctico. Su contenido nunca avanza hacia diferencias cualitativas, por el contrario aísla al sustantivo principal de los significados que lo pueden invalidar y promueve una identificación inmediata del interés particular con el general. Los juegos del lenguaje en esta lógica buscan que el receptor asuma una estructura acrítica de las problemáticas en cuestión y que reaccione ante ellas de una manera fija y específica. Así, advertiría Marcuse ya en los años sesenta, éste "tiende a expresar y auspiciar la identificación inmediata entre razón y hecho, verdad y verdad establecida, esencia y existencia, la cosa y su función" (1985, p. 115). Dichas equivalencias con el tiempo impiden el desarrollo integral del sentido y finalmente se convierten en los rasgos dominantes del comportamiento social y político de quienes las asumen como verdades absolutas. Cabe decir que las expresiones de descontento que han 
tenido lugar en países como Argentina, Bolivia o Ecuador, en lo que va del siglo XXI, demuestran que estas fuerzas reactivas, además, tienen la capacidad de incorporar el lenguaje los simbolismos y las formas de acción de sus opositores (Levy y Rebón, 2020).

Los sentidos construidos alrededor de los referentes empíricos estudiados se han configurado, entre otros aspectos, debido a las atribuciones colectivas de todos los grupos implicados y, desde luego, de los actos autónomos y/o coordinados de sus simpatizantes. La razón mentada, en lo que se refiere a las acciones de los demandantes, es el producto de organizaciones y colectivos que se aglutinan de forma regular en torno a necesidades y a condiciones adversas específicas, que de algún modo los atraviesan por igual. En Chile, por ejemplo, puede que el detonante haya sido la acción colectiva de los estudiantes de secundaria ante el incremento del pasaje del metro, pero esas reivindicaciones, en cuestión de días, fueron incorporadas por otros sectores de la sociedad y se matizaron con sus consignas y luchas en relación a un enemigo común: el Estado. Los treinta pesos que implicaba el aumento del tiquete fueron vinculados con treinta años de tiranía estatal, con la alta renta y la elevada desigualdad social en el país.

Las acciones colectivas inherentes a la protesta en ese país se nutrieron así de demandas contra el régimen tributario y pensional, contra la privatización del agua, y de reclamos a favor de la vivienda, la salud y la educación. Estas consignas se articularon con enmarcados prevalecientes acuñados por colectivos y organizaciones de activistas que también desafiaban el orden instituido; verbigracia "un violador en tu camino" del colectivo de género "LASTESIS" (Salamanca, 2020, enero 09). En este contexto, como en los demás casos, se configuraron marcos maestros que reunían demandas multisectoriales y que fungieron como lema nacional. Ejemplo: "no podemos parar la lucha si todavía no vemos cambios importantes por parte del gobierno. Queremos una nueva constitución y que se vaya Piñera” (BBC, 2019, noviembre 09).

El gobierno y sus simpatizantes no tardaron en calificar de vándalos y "antisociales" a los descontentos y tomar cartas en el asunto. En un comienzo el primer mandatario afirmo textualmente:

Estamos en guerra contra un enemigo poderoso e implacable que no respeta a nada ni a nadie y que está dispuesto a usar la violencia sin ningún límite, incluso cuando significa la pérdida de vidas humanas, con el único propósito de producir el mayor daño posible. (La Nación, 2019, octubre 21)

Más tarde incluso llegó a asegurar que las acciones, además, eran parte de las estrategias del "Foro de Sao Paulo"8 para desestabilizar las democracias latinoame-

8 Se trata de una organización que fundó el Partido de los Trabajadores de Brasil en 1990, tras la caída del Muro de Berlín el año anterior. Fue integrada por partidos, movimientos políticos, organizaciones sociales, dirigentes comunitarios, líderes sociales, campesinos e indígenas afines a la izquierda Latinoamericana. Y se pensó tanto para discutir las problemáticas de este territorio, como para articular los esfuerzos y las comunicaciones que dichos grupos tenían en cada país. 
ricanas. El argumento también lo implementó el establecimiento colombiano para deslegitimar y negar las demandas de su población; allí el ejecutivo, otorgando un carácter partidista a la indignación, señalo a los sectores de la oposición como sus autores y los enmarcó como "pirómanos" por "pretender ganar con la violencia lo que no ganaron en las urnas" (Manetto, 2019, s. pág.). De acuerdo con el historiador Roberto González, en este país el Estado satura a la población de "información, de incertidumbres y de mentiras que se repiten de boca en boca y de pantalla en pantalla" hasta que un grueso de adeptos las asumen y luchan por ellas, incluso recurriendo a la violencia contra los que consideran contrarios (González, 2019, s. pág.). En países como Ecuador el estatu quo culpó a la administración anterior y a su líder Rafael Correa del estallido social que lo llevó al borde de la crisis administrativa. En Bolivia el gobierno de facto, haciendo uso de los medios de comunicación a su disposición, instaló en el imaginario social subjetividades dirigidas a erosionar la imagen del mandatario destituido (Lizárraga y Vacaflores, 2019). En esta República salta a la vista la instrumentalización de los valores morales para manipular a las masas en contra de las reivindicaciones; allí se declaró la expulsión de la bandera "Wiphala" del palacio de gobierno y el retornó de la biblia en su reemplazo.

El orden moral lo instauran tanto la ciencia como la ley (Gusfield, 2014): en la primera instancia tienen lugar las acciones de los sectores diferenciados de la sociedad en términos de capital intelectual y de experiencia en asuntos públicos (ejemplo, especialistas en temas diversos o personajes influyentes en la vida pública); en la segunda intervienen las acciones de las instituciones que se encargan de hacer las leyes y de las que representan la justicia (ejemplo las cámaras de legisladores o las fiscalías). En el caso boliviano las narrativas que instalaron académicos, actores políticos y medios de comunicación alineados al golpe, estuvieron dirigidas a maquillarlo "encubriendo la violencia y criminalizando la protesta de los sujetos comunitarios” (Lizárraga y Vacaflores, 2019, quinto párrafo). Poco tiempo después del golpe de Estado el nuevo régimen desarrolló toda una normatividad jurídica para legitimarse.

En esos ambientes la conceptualización determina las categorías mediante las cuales se percibe el orden social y por lo tanto el carácter de los conflictos que subyacen a las demandas de los indignados. De esta forma el término "protesta" -y las acusaciones que resuenan entre los actores implicados- se reproduce en los espacios de interacción social, acompañado de juegos de lenguaje, que se enuncian mediante unas convenciones gramaticales puntuales y se nutren de los signos y símbolos impresos en la cultura particular de cada contexto. Las problemáticas denunciadas se despliegan en la conciencia de los ciudadanos y del público entiéndase de las personas, organizaciones e instituciones directamente afectadas que comparten percepciones respecto de las situaciones problemáticas y sus consecuencias- a través de un proceso de problematización, y publicización de la situación (Cefaï, 2014), que a su vez entraña una dimensión moral y otra cognitiva. "El aspecto cognitivo consiste en las creencias sobre el aspecto fáctico de la situación y los acontecimientos que constituyen el problema (...) El aspecto moral permite que la situación sea considerada dolorosa e inmoral” (Gusfield, 2014, p.75). El sentido, en suma, hace deseable la erradicación del malestar o su persistencia, es decir, le otorga el estatus de problemas públicos a las demandas enarboladas, pero 
también justifica las posturas de los actores que se encuentran a favor o en contra de las acciones de confrontación, y explica la mutación de éstas en otras formas de intervención e insurrección.

\section{Acciones estatales}

Entre las acciones de confrontación más recurrentes y efectivas de la protesta social se encuentran la alteración del orden y el daño a bienes públicos o privados. Las dos son comprensibles dado que su esencia es desafiar el poder hegemónico, aunque también son cuestionables en cuanto causan perjuicios a terceros; de hecho la trifulca entre los actores pasa por este tema. Los repertorios implementados para ello dependen de la coyuntura y de la época. El ímpetu se convierte en medio cuando los Estados se tornan autoritarios, inhumanos y herméticos a los fines (léase denuncias y demandas). En Colombia, país que vive tiempos de "postconflicto", se escuchó la consigna "protesta pacífica" y se intentó instalar una cultura de la revuelta sin desmanes, desde diferentes sectores de la sociedad; hace poco más de cincuenta años las condiciones fueron favorables a la salida armada. A lo largo de la historia de la protesta, en general, se han realizado ataques a casas de figuras públicas o de malhechores, quemas de mercancías, asaltos a graneros, destrozos de máquinas modernas ${ }^{9}$, barricadas, sentadas, piquetes, etc. (Tilly y Wood, 2010). Hoy por hoy son comunes los saqueos a consorcios empresariales y comerciales, así como los daños a inmuebles de sedes bancarias, medios de información e instituciones públicas.

Al permanecer sentados, de pie o marchando junto a otros agresivamente en un espacio público, los manifestantes afirman su identidad y refuerzan su solidaridad. Al mismo tiempo, la alteración del orden obstruye las actividades rutinarias de sus oponentes, de los observadores o de las autoridades y les fuerza a atender las demandas de los manifestantes. Finalmente permite que se amplíe el círculo del conflicto. Mediante el bloqueo del tráfico o la interrupción de los asuntos públicos, los manifestantes crean molestias a terceros, suponen un riesgo para la ley y el orden e implican a las autoridades en un conflicto privado. (Tarrow, 2004, p. 142)

En esta instancia la actuación del Estado es crucial pues puede suprimir o catapultar los ánimos hasta radicalizarlos: en Ecuador se articuló la "guardia indígena” para enfrentar a la fuerza pública; en Chile la represión despertó los traumas emocionales de la dictadura pinochetista y desató la furia de los manifestantes; a propósito en las ciudades ese país reinó un caos que tardó días en ser controlado, pese a la pronta intervención de militares y carabineros (La Nación, 2019, octubre 21). Allí, al igual que en Colombia, a razón de las confrontaciones, se conformó un frente de defensa llamado "primera línea", grupo que veló por la protesta pacífica,

9 Esta tendencia se caracterizó por el rechazo a la implementación de maquinaria moderna en los procesos de producción. Su desarrollo tuvo lugar durante las primeras décadas del siglo XIX; sus repertorios de acción consistían en la destrucción de los nuevos artefactos. 
la contención de las acciones antidisturbios y la protección de abusos represivos contra los manifestantes (El Espectador, 2019, diciembre 11).

El establecimiento responde aplicando estrategias que apagan los ánimos de los insumisos, una de ellas es el aumento de los "costes de la movilización". En conformidad con Ortiz, la coacción del Estado es una forma singular de control político cuyo propósito consiste en disminuir las posibilidades y desafíos directos al poder.

Por lo tanto, la represión estatal a las movilizaciones se puede manifestar de formas muy diversas, que van desde las formas no violentas y encubiertas a las violentas y hostiles (por ejemplo, hostigamiento, censura, detenciones, amenazas, violencia policial, desapariciones forzadas, masacres), pueden ser llevadas a cabo por diferentes actores (por ejemplo, fuerzas armadas, fuerzas policiales, escuadrones de la muerte), en diferentes niveles (nacional, estatal o provincial y local) y sus características pueden variar según el tipo de régimen (...) o el oponente. (Ortiz, 2017, p. 81, 82)

La práctica tipo ideal consiste en disolver las manifestaciones con el uso de las fuerzas armadas y en judicializar a los sublevados. El detonante -la justificación recurrente por excelencia- es la violencia durante la confrontación. Ésta se desata por forcejeos, provocaciones o brotes de vandalismo, en algunas oportunidades ejercido por los propios organismos de orden público, en muchas otras por las facciones más radicales entre aquellos. Se aplica, por parte de gobiernos autoritarios pero también de gobiernos democráticos, mediante la intervención de las instituciones policiales, en contextos dispares, con el uso injustificado, inadecuado y desmedido de la fuerza.

Estos organismos actúan mediante operativos de dispersión de masas a gran escala utilizando armamentos que denominan como "armas para el control de multitudes", "armas para el control de disturbios", "armas no letales" o "armas menos que letales". De acuerdo con un informe presentado en 2016 por la Red Internacional por los Derechos Civiles (INCLO), las organizaciones que la integran, y la Physicians for human Rights (PHR): en muchas oportunidades "también se ha observado que se las utiliza como instrumento de represión política para desalentar, desmotivar, intimidar, lastimar y matar a los manifestantes en lugar de servir como herramienta para la gestión más segura de las manifestaciones" (PHR International Network of Civil Liberties Organizations, 2016, p. 14). El arsenal incluye proyectiles de energía cinética, agentes químicos irritantes, camiones hidrantes, granadas de aturdimiento, dispositivos acústicos de largo alcance, dispositivos de conducción eléctrica y armas de energía hídrica, entre otras.

Respecto al caso ecuatoriano la Human Rights Watch (HRW) presentó un informe en donde indicó que los agentes de policía de ese país realizaron un uso indiscriminado de la fuerza contra manifestantes arrojando gases lacrimógenos en espacios cerrados, provocando asfixia, disparando cartuchos a corta distancia y, en algunos casos, apuntando a la cabeza de los manifestantes causándoles daños 
oculares. La comunicación señala que los cartuchos lacrimógenos usados por la policía estaban vencidos, lo cual puede alterar la composición química del gas e incrementar la probabilidad de asfixia (HRW, 2020). En relación al caso chileno la Comisión Internacional de Derechos Humanos condenó el uso excesivo de la fuerza y llamó a las autoridades a su cese inmediato. Según los informes, de las 26 muertes, ocurridas a diciembre 06 de 2019, cinco habrían sido por acción directa de agentes del Estado, y 283 personas presentaban problemas en los ojos debido al impacto de perdigones o bombas lacrimógenas usadas por carabineros (La Nación, 2019, diciembre 06).

Otra maniobra estatal -un poco menos violenta pero no menos controversialconsiste en atraer a los líderes a la cumbre del sistema político y en retardar sus demandas o en paliarlas con salidas vertiginosas. Igualmente es frecuente que los grupos que detentan el poder denuncien a la oposición, o a los sectores adversos, como los autores intelectuales o materiales de las reclamaciones y de sus consecuencias, recurriendo al reduccionismo de las problemáticas o a su negación. Para ello hacen recortes de la realidad y los interpretan con una lectura favorable a sus propios intereses; en esta práctica el miedo, el uso de los medios de comunicación y la manipulación ideológica de las masas es instrumental a la docilidad de los partidarios en potencia. En la mayoría de estados nacionales las altas esferas del poder han alimentado durante décadas la idea de que la protesta social siempre ha estado orquestada por la subversión; en Colombia, por ejemplo, se la ha vinculado por años al accionar de grupos guerrilleros.

Así mismo, es habitual la desarticulación de los descontentos mediante la cooptación de sus líderes, o de las organizaciones de base, otorgándoles beneficios individuales, corporativos o gremiales. Sin embargo, el procedimiento recurrente, ya sea en tiempos de ebullición o en tiempos de reflujo social, se basa en el etiquetado peyorativo de los actores -sean líderes o grupos-, en la regulación de las manifestaciones y en la criminalización de su práctica. En esa lógica se suele afirmar que las movilizaciones son actos de terrorismo y los gobiernos elaboran leyes, proyectos de ley, reglamentos e interpretaciones jurídicas que tienen por fin constreñirlas. Los criterios, entre otras cosas, contemplan el aviso previo para realizar movilizaciones en ciertos horarios y días de la semana; el uso de espacio público delimitado; los motivos para la intervención de las fuerzas armadas y la penalización de acciones y conductas.

A lo largo del desarrollo de todos los casos examinados se ordenó el despliegue de las fuerzas armadas y se dispuso toque de queda; particularmente en Chile el presidente decretó "Estado de emergencia” (Garretón, 2019). En trayectoria histórica, de acuerdo con el informe del Centro de Estudios Legales y Sociales (2016), en Venezuela, en 2005, una reforma del código penal estableció la ilegalidad de los cierres de calles por parte de manifestantes; en Colombia en 2011 se tipificó ese delito con la "Ley de Seguridad Ciudadana" y en 2013 el ministerio de Defensa presentó un proyecto de ley para ampliar esos tipos penales; en Brasil, en el mismo año, cuando las protestas masivas se precipitaron en las principales ciudades del país, se presentaron más de una docena de iniciativas legislativas en el Congreso Nacional y en las legislaturas de los estados y municipios; en México ocurrió otro 
tanto luego de las manifestaciones en torno a la desaparición de los estudiantes en Ayotzinapa en 2014; y en Argentina, también en 2014, diez proyectos de ley buscaron regular las manifestaciones.

\section{Conclusiones}

En una época en donde las sociedades se tornan cada vez más complejas y pluralistas, y los Estados se muestran incapaces de responder de forma adecuada a las necesidades subyacentes, no es de extrañar que la protesta social represente una instancia de libertad -de participación política directa- para expresar la voluntad general de quienes no tienen voz. De hecho, su recurrencia es más que obvia mientras que su agotamiento expresa el anquilosamiento del sistema democrático, dadas las tensiones que se generan entre los grupos de interés que conforman la sociedad.

Desde el punto de vista conceptual este fenómeno es una forma de acción social colectiva que entraña expresiones propias de los movimientos sociales y en ocasiones los desencadena. Con el paso del tiempo su práctica se ha transformado, ha resultado fundamental para el desarrollo de las repúblicas democráticas y representa un presupuesto elemental para su continuidad. Su emergencia es producto de las tensiones internas de la estructura social y de los grupos y organizaciones que la componen. Su fisonomía depende en buena medida del acervo cultural, de las coyunturas políticas y de las decisiones que se toman en los espacios de poder. Su desarrollo pasa por la creación de organismos de articulación en los cuales se problematiza la realidad, se sugieren acciones y se promueven actos de unidad. Y adquiere su sentido de acuerdo a la realidad empírica mediante gramáticas públicas.

En los casos abordados se destacan la conformación de estructuras organizativas, la atribución de significados, las dinámicas de movilización y las acciones estatales, allende a las circunstancias y a la heterogeneidad sociocultural de los países en los que tuvieron lugar. El examen comparado de estos procesos, como se pudo ver, develó patrones de ejecución que varian de acuerdo al contexto pero que se reproducen una y otra vez en el desarrollo de las confrontaciones. Las variaciones permiten poner en discusión las semejanzas y diferencias de las acciones colectivas inherentes, así como sus innovaciones en materia de transformación, en relación a otras épocas.

Sin embargo, apreciando las consecuencias -en Haití se obtuvo un éxito parcial; en Puerto Rico y Ecuador los indignados lograron sus propósitos; en Chile no se logró la destitución del presidente pero se allanó el camino para reformar la carta magna; en Bolivia hubo que esperar a unas nuevas elecciones presidenciales para revertir el golpe de Estado; y en Colombia únicamente se logró frenar la reforma pensional y laboral- resta preguntarse por qué en todos los casos el desarrollo de los procesos no tiene el mismo resultado y observar las condiciones específicas, como la composición de los grupos, su ubicación dentro de la estructura social, el acceso a los recursos disponibles o los bienes públicos en juego, entre otras. 


\section{Referencias bibliográficas}

Almeida, P. y Cordero, A. (eds.). (2017). Movimientos sociales en América Latina. Perspectivas tendencias y cosas. CLACSO.

Archila, M. (2018). Idas y venidas vueltas y revueltas. La Protesta Social en Colombia 1958-1990. Siglo del Hombre Editores. CINEP.

BBC (16 de noviembre de 2018). Camilo Catrillanca: la muerte en Chile de un joven mapuche por disparos de la policía que causa controversia y protestas. Redacción BBC News mundo.

https://www.bbc.com/mundo/noticias-america-latina-46231136

BBC (15 de febrero de 2019). Protestas en Haití cómo las manifestaciones contra el gobierno acabaron en una violenta crisis en el país más pobre de Occidente. Redacción BBC News mundo. https://www.bbc.com/mundo/noticias-america-latina-47234523

BBC (09 de noviembre de 2019). Protestas en Chile I "No podemos parar la lucha": la movilización contra el gobierno se sostiene en su tercera semana. Redacción BBC News mundo. https://www.bbc.com/mundo/noticias-america-latina-50355752

Bobbio, N. (2014). El futuro de la democracia. Fondo de Cultura Económica.

CNN. (29 de octubre de 2019). Abecé de las protestas en Bolivia: ¿quiénes protestan, por qué y qué piden? https://cnnespanol.cnn.com/2019/10/29/ abece-de-las-protestas-en-bolivia-quienes-protestan-por-que-y-que-piden/

Camus, A. (2015). El hombre rebelde. Grupo Editorial Tomo.

Calderón, F. (coord.). (2012). La protesta social en América Latina. Cuadernos de prospectiva política. Siglo Veintiuno Editores S.A.

Castells, M. (2009). Comunicación y poder. Alianza.

Castro, L. (2018). Movimientos sociales: herramientas conceptuales. Estudios Políticos y Estratégicos, 6 (2), (pp. 36-57). https://revistaepe.utem.cl/ articulos/movimientos-sociales-herramientas-conceptuales/

Cefaï, D. (2008). Los marcos de la acción colectiva. En A. Natalucci (Ed.), Sujetos, movimientos y memorias. Sobre los relatos del pasado y los modos de confrontación contemporáneos, (pp. 49-79). Al Margen.

Cefaï, D. (2014). Investigar los problemas públicos: con y más allá de Joseph Gusfield en J. Gusfield, La cultura de los problemas públicos (pp. 11-60). Siglo XXI Editores.

Centro de Estudios Legales y Sociales (2016). Los Estados Latinoamericanos frente a la protesta social. 
Diani, M. (2015). Revisando el concepto de movimiento social. Encrucijadas Revista Crítica de Ciencias Sociales, N. 9, (pp. 1-16).

El Espectador (24 de julio de 2019). Gobernador de Puerto Rico dice que renuncia a partir del 2 de agosto. Redacción Internacional, El Mundo.

https://www.elespectador.com/noticias/el-mundo/gobernador-de-puertorico-dice-que-renuncia-partir-del-2-de-agosto-articulo-872661

El Espectador (11 de diciembre de 2019). Así funciona la primera línea chilena, el grupo que vela por la protesta pacifica. Redacción Internacional con información de AFP, El Mundo.

https://www.elespectador.com/noticias/el-mundo/asi-funciona-la-primeralinea-chilena-el-grupo-que-vela-por-la-protesta-pacifica-articulo-895287

Escandar, A. (21 de octubre de 2017). Multitudinaria movilización por Santiago Maldonado a la Plaza de Mayo. Política. https://www.infobae.com/ politica/2017/10/21/arranca-una-nueva-marcha-por-santiago-maldonado-aplaza-de-mayo/

Fillieule, D. y Tartakowsky, O. (2020). La manifestación: el origen de una forma de protesta. Nueva Sociedad, 286, (pp. 62-77) https://nuso.org/revista/286/la-globalizacion-de-la-protesta/

Galeano, E. (2015). Las venas abiertas de América Latina. Siglo XXI editores.

Garretón, A. (25 de octubre de 2019). En Chile se inicia un ciclo que exige un nuevo pacto político y social. Río Negro.

https://www.rionegro.com.ar/manuel-garreton-en-chile-se-inicia-un-cicloque-exige-un-nuevo-pacto-politico-y-social-1150616/

Gil, F. (12 de noviembre de 2019). El corset chileno: no son 30 pesos, son 30 años. Diario Página 12, El Mundo. https://www.pagina12.com. ar/230416-el-corset-chileno-no-son-30-pesos-son-30-anos

González, R. (2019). "Las estrategias del Estado para estigmatizar la protesta social persisten con otros apellidos”. Revista Arcadia, (s.p.).

https://www.revistaarcadia.com/agenda/articulo/roberto-gonzalez-aranahabla-del-paro-nacional-de-noviembre-en-colombia/79224

Gusfield, J. (2014). La cultura de los problemas públicos. Siglo XXI Editores Argentina S.A.

Human Rights Watch. (06 de abril de 2020). Ecuador: Lecciones de las Protestas de 2019. https://www.hrw.org/es/news/2020/04/06/ ecuador-lecciones-de-las-protestas-de-2019

Infobae. (07 de julio de 2018). Miles de personas se manifestaron en Colombia para rechazar los asesinatos de líderes sociales. Infobae con información EFE. https://www.infobae.com/america/colombia/2018/07/07/miles-de-personasse-manifestaron-en-colombia-para-rechazar-los-asesinatos-de-lideressociales/ 
Infobae. (21 de noviembre de 2019). La huelga nacional en Colombia se cerró con un cacerolazo masivo en todo el país. Infobae con información APF y EFE. https:// www.infobae.com/america/colombia/2019/11/21/colombia-choques-entreestudiantes-y-la-policia-en-los-alrededores-del-aeropuerto-de-bogota/

La Izquierda Diario. (25 de julio de 2019). Residente y Bad Bunny le ponen música a las protestas en Puerto Rico. Cultura. https://laizquierdadiario.com/ Residente-y-Bad-Bunny-le-ponen-musica-a-las-protestas-en-Puerto-Rico

La Nación. (06 de diciembre de 2019). CIDH censura "uso excesivo de fuerza" para reprimir protestas en Chile. La Nación AFP. https://www.nacion. com/el-mundo/politica/cidh-censura-uso-excesivo-de-fuerza-para/ FAKUYFNJFFHNJC536YC2SVJIEI/story/

Levi, G. y Rebón, J. (12 de febrero de 2020). Entrevista a Álvaro García Linera: "La lucha por la igualdad tiene un alto costo social y alguien te lo va a cobrar tarde o temprano". Espoiler. http://espoiler.sociales.uba.ar/2020/02/12/entrevistaa-alvaro-garcia-linera-la-lucha-por-la-igualdad-tiene-un-alto-costo-social-yalguien-te-lo-va-a-cobrar-tarde-o-temprano/

Lizárraga, P. y Vacaflores, C. (16 de noviembre de 2019). La whipala y las balas. El Golpe de Estado y la Resistencia de los Pueblos. $\quad$ Espoiler. $\quad$ http://espoiler.sociales.uba.ar/2019/11/16/ la-whipala-y-las-balas-el-golpe-de-estado-y-la-resistencia-de-los-pueblos/

Marcuse, H. (1985). El hombre unidimensional. Editorial planeta.

McAdam, D. (1999). Orígenes terminológicos, problemas actuales, futuras líneas de investigación. En McAdam, D., McCarthy, J. y Zald, M. (Eds.) Movimientos sociales: perspectivas comparadas. Oportunidades politicas, estructuras de movilización y marcos interpretativos culturales, (pp. 49-70). Ediciones Istmo.

Melucci, A. (2010). Acción colectiva, vida cotidiana y democracia. El Colegio de México.

Manetto, F. (28 de noviembre de 2019). Las protestas en Colombia buscan redoblar la presión al Gobierno. El País. https://elpais.com/internacional/2019/11/27/ colombia/1574889343_816527.html

Miranda, B. (07 de noviembre de 2019). Protestas en Bolivia tras la cuestionada victoria de Evo Morales: cómo se radicalizaron las manifestaciones y la violencia en el país. BBC News Mundo Bolivia. https://www.bbc.com/mundo/ noticias-america-latina-50333889

Mouffe, C. (2011). La política y lo político. En En torno a lo político, (pp. 15-40). Fondo de Cultura Económica.

Mouffe, C. (2014). ¿Qué es la política agonista? En Agonística, (pp.21-35). Fondo de Cultura Económica. 
Montes, R. (18 de enero de 2020). Aumenta el rechazo al mundo político a los tres meses delacrisis en Chile. ElPaís. https://elpais.com/internacional/2020/01/18/ america/1579370590_207046.html

Munck, G. (1995). Algunos Problemas Conceptuales en el Estudio de los Movimientos Sociales. Revista Mexicana de Sociología, (3), (pp.16-40).

El Nuevo Día. (21 de julio de 2019). Con 'cacerolazo' piden renuncia del Gobernador de Puerto Rico. El Nuevo Día Internacional. http://www.elnuevodia.com.co/ nuevodia/mundo/internacional/436334-con-cacerolazo-piden-renuncia-delgobernador-de-puerto-rico

Olson, M. (1992). La lógica de la acción colectiva. Bienes públicos y la teoría de los grupos. Ed. Limusa, grupo Noriega editores.

Ortiz, D. (2017). Represión estatal y movilización en América Latina. En P. Almeida, y A. Cordero (eds.). Movimientos sociales en América Latina. Perspectivas tendencias y cosas, (pp. 81-112). CLACSO.

Oquendo, C. (27 de julio de 2019). Colombia marcha por los líderes sociales asesinados. El País. https://elpais.com/internacional/2019/07/27/ colombia/1564196965_977885.html

Paul, F. (21 de octubre de 2019). Protestas en Chile: 4 claves para entender la furia $y$ el estallido social en el país sudamericano. La Nación/BBC News. https://www.lanacion.com.ar/el-mundo/ protestas-chile-4-claves-entender-furia-estallido-nid2299035

Physicians for Human Rights - International Network of Civil Liberties Organizations. (Ed.). (2016). Letalidad encubierta. Efectos en la salud del uso de las armas "menos letales" en las protestas.

Quirós, J. (2014). Palabras de democracia. En A. Adelstein y G. Vommaro, (coord.). Diccionario del léxico corriente de la política Argentina (1983-2013). Universidad Nacional General Sarmiento.

Saccone, V. (25 de septiembre de 2019). La lucha del Movimiento Sin Tierra de Brasil por sobrevivir. France 24, en foco. https://www.france24.com/ es/20190924-en-foco-brasil-trabajadores-sin-tierra-arroz

Salamanca, N. (09 de enero de 2020). "Un violador en tu camino", la llama que despertó la cuarta ola del feminismo. UN periódico digital.

https://unperiodico.unal.edu.co/pages/blog/detail/un-violador-en-tucamino-la-Ilama-que-desperto-la-cuarta-ola-del-feminismo/

Semana. (15 de octubre de 2019). Cinco factores que desataron en Ecuador la crisis política y social más álgida de su historia reciente. Mundo. https://www.semana.com/mundo/articulo/cinco-momentos-clave-de-lacrisis-politica-que-mantuvo-a-ecuador-convulsionado-por-12-dias/636143 
Semana. (08 de diciembre de 2019). "La humanidad entera, que entre cadenas gime”, el clamor con que terminó \#UnCantoXColombia. Mundo. https://www. semana.com/nacion/articulo/minuto-a-minuto--la-humanidad-entera-queentre-cadenas-gime-el-clamor-con-que-termino-uncantoxcolombia/644037

Snow, D., Rochford, B., Worden, S. y Benford, R. (1986). Procesos de alineamiento de marcos, micromovilización y participación en movimiento. En Chihu, A. (Coord.) (2006). El análisis de los marcos en la sociología de los movimientos sociales. (pp. 31-82). Universidad Autónoma Metropolitana.

Snow, D. y Benford, R. (1988). Ideología, resonancia de marcos y movilización de participantes. En A. Chihu (Coord.) (2006). El análisis de los marcos en la sociología de los movimientos sociales (pp. 83-117). Universidad Autónoma Metropolitana.

Snow, D. y Benford, R. (1992). Marcos maestros y ciclos de protesta. En Chihu, A. (Coord.) (2006). El análisis de los marcos en la sociología de los movimientos sociales. (pp. 119-153), Universidad Autónoma Metropolitana.

Suárez, A. (27 de noviembre de 2019). Colombia, ¿país con tradición de protestas? France 24. https://www.france24.com/es/ historia/20191127-protestasencolombia-ivanduque-hartazgosocial-1

Tarrow, S. (2004). El poder en movimiento Los movimientos sociales, la acción colectiva y la política. Alianza editorial, S.A.

Tilly, C. (2000). Acción colectiva. Apuntes de investigación del Grupo de Estudios en Cultura, Economía y Política, 6, (pp. 9-32).

Tilly, C. y Wood, L. (2010). Los movimientos sociales 1768-2008. Editorial Crítica.

Weber, M. (2002). Economía y sociedad. Esbozo de sociología comprensiva. Fondo de Cultura Económica.

Weber, M. (1990). Sobre algunas categorías de la sociología comprensiva (1913) en M. Weber, Ensayos sobre metodología sociológica. (pp. 175-221). Amorrortu editores S.A.

Wittgenstein, L. (2017). Tractatus lógico-philosophicus. Investigaciones filosóficas. Gredos. 


\section{Fuentes de información no citadas}

Ávila, A. (27 de noviembre de 2019). Algunas conclusiones sobre las dinámicas del Paro Nacional. Semana. https://www.semana.com/opinion/articulo/algunasconclusiones-sobre-las-dinamicas-del-paro-nacional-columna-de-arielavila/642362

Fleitas, G. (29 de febrero 2020). 'Chile despertó', un 'tour' de arte inspirado por la revuelta. El Tiempo. https://www.eltiempo.com/mundo/latinoamerica/ protestas-en-chile-chile-desperto-un-tour-de-arte-inspirado-por-larevuelta-467660

Gómez, J. (O3 de enero de 2020). Las protestas de 2019 en Haití, ¿cambiarán en 2020 el 'statu quo' de la is/a? France 24. https://www.france24.com/ es/20200103-las-protestas-de-2019-en-hait\%C3\%AD-cambiar\%C3\%A1n-en2020-el-statu-quo-de-la-isla

Quijada, N. (19 de mayo de 2020). Regresan las intervenciones en la Torre Telefónica con mensajes acerca de la pandemia del covid-19. Emol. https://www. emol.com/noticias/Espectaculos/2020/05/19/986647/Torre-Telefonicaintervenciones-coronavirus-pandemia.html

Rebón, J. (2019). La política en las calles. Aproximaciones desde la Argentina reciente. Revistas de ciencias sociales. 32 (44), 15-42 http://dx.doi.org/10.26489/rvs.v32i44.1

Romero, M. (28 de octubre de 2019). Nuevajornada de protestas antigubernamentales en Haiti deja dos muertos. France 24. https://www.france24.com/ es/20191028-protestas-haiti-combustible-energia-violencia

Salazar, G. (2012). Movimientos sociales en Chile. Trayectoria histórica y proyección política. Uqbar Editores. 